International Journal of Osteoarchaeology

Int. J. Osteoarchaeol. 20: 317-334 (2010)

Published online 2 April 2009 in Wiley InterScience

(www.interscience.wiley.com) DOI: 10.1002/oa.1044

\title{
A Metric Study of Three Types of Artificial Cranial Modification from North-Central Peru
}

\author{
EMMA POMEROY, ${ }^{a *}$ JAY T. STOCK, ${ }^{a}$ \\ SONIA R. ZAKRZEWSKI ${ }^{b}$ AND MARTA MIRAZÓN LAHR ${ }^{a}$ \\ a Leverhulme Centre for Human Evolutionary Studies, Department of Biological \\ Anthropology, University of Cambridge, Fitzwilliam Street, Cambridge, CB2 1QH, UK \\ b Department of Archaeology, University of Southampton, Avenue Campus, Highfield, \\ Southampton, SO17 1BF, UK
}

Artificial cranial modification (ACM) involves the alteration of cranial vault shape by cultural means, and is performed during infancy while the cranial bones remain soft and malleable. The direction of normal cranial growth is altered through the application of external forces. In this study, three types of ACM from north-central Peru (posterior flattening, bilobed and circumferential) were analysed using standard craniometric techniques. The aim was to determine the effects of these forms of ACM on craniofacial morphology, and the extent to which different types of ACM could be distinguished from one another and unmodified crania on the basis of these measurements. Significant differences between artificially modified and unmodified crania, and between different types of ACM, were demonstrated in cranial vault shape for all types. Significant differences in facial morphology were found only in the bilobed group compared with the unmodified crania. Canonical variates analysis (discriminant analysis) confirmed that major differences between modification types and unmodified crania were in measurements and angles of the cranial vault. While the results show some similarities to previous studies, they add to the variability in the patterns and extent of differences documented to date. It is suggested, based on these results and visual observations, that interpopulation variation in ACM within major modification categories may explain some of the variability in results between studies, an explanation which has previously received insufficient recognition but which remains to be tested since varied methodology between studies may also be a contributory factor. While previous studies have often sought to generalise about the effects of ACM, the examination of the differences between populations even within major ACM categories may offer new insight into cultural variation in modification techniques between populations and the nature of craniofacial development. Copyright (c) 2009 John Wiley \& Sons, Ltd.

Key words: artificial cranial modification; craniometrics; Peru

\section{Introduction}

Anatomically, artificial cranial modification (ACM) is 'the product of the dynamic distortion

* Correspondence to: Leverhulme Centre for Human Evolutionary Studies, Department of Biological Anthropology, University of Cambridge, Fitzwilliam Street, Cambridge, CB2 1QH, UK.

e-mail: emma.pomeroy@cantab.net of the normal vectors of infantile neurocranial growth through the agency of externally applied forces' (Gerszten, 1993: p. 87). The restriction of cranial growth in certain directions results in compensatory growth in other less restricted or unrestricted directions (Aufderheide \& RodríguezMartín, 1998) and thus alteration of cranial shape. The direction of growth, rather than its 
magnitude, is affected (Moss, 1958) and the brain achieves a volume comparable to unmodified crania (Aufderheide \& Rodríguez-Martín, 1998).

ACM has had a surprisingly broad distribution throughout the world, being found on every inhabited continent at some stage in the past (e.g. Hrdlička, 1922; Dingwall, 1931; Blackwood \& Danby, 1955; Brown, 1981; Antón \& Weinstein, 1999; Ozbek, 2001). It has been suggested for the Dynasty of Akhenaten in ancient Egypt (Snorrason, 1946), and was common in certain districts of 19th century France (Dingwall, 1931). The earliest certain cases of ACM come from Late Palaeolithic Australia and China (Brothwell, 1975; Brown, 1981; Clark et al., 2007).

To produce permanent effects, ACM must be performed during infancy when the cranial bones are malleable and when the trajectory of growth can be controlled (Dingwall, 1931; Torres-Rouff, 2002). It is therefore not a feature acquired through individual choice (Torres-Rouff, 2002), but rather that of parents or carers. An exception might be cradle-boarding or laying the infant with its head on a hard surface for long periods, which unintentionally flattens the occipital region (Dingwall, 1931; Moss, 1958; Mason, 1887). Methods of intentionally modifying crania are more varied and the effects generally more pronounced. Cloth or other material may be used, sometimes with boards, pads, bags of earth or clay or even special headdresses (Dingwall, 1931; Allison et al., 1981).

The suggested motives for intentional ACM are varied, but not mutually exclusive. ACM may symbolise social identity, as some Spanish chroniclers suggested for the Andean region (Aufderheide \& Rodríguez-Martín, 1998). It can serve as both a permanent symbol of intra-group solidarity and of inter-group cultural differences (Torres-Rouff, 2002). As such, it may be useful in archaeological studies of inter-group interactions (e.g. Torres-Rouff, 2002). Cultural notions of attractiveness (Hatt, 1915; Dingwall, 1931; Blackwood \& Danby, 1955) and supposed health benefits (Hatt, 1915) have also been cited as reasons for the practice, although such explanations have not generally received strong support in subsequent work. However, Blackwood \& Danby (1955) present ethnographic evidence from Melanesia that ACM was considered to increase an individual's physical attractiveness. This provides valuable insight to a practice that had largely died out worldwide during the 20th century

The purpose of this study is twofold: (1) to examine metrically the effects of different types of ACM on morphology in order to assess the way in which they can be distinguished metrically $_{i}(2)$ to investigate the extent to which different forms of cranial modification influence facial morphology. The cranium may be considered a functional matrix comprising numerous series of interacting functional units (Moss, 1958; Antón, 1989). Growth restriction in the cranial vault therefore indirectly affects growth in other areas such as the cranial base and face (see Blackwood \& Danby, 1955; Moss, 1958; Bjork \& Bjork, 1964; Schendel et al., 1980; Brown, 1981; Antón, 1989; Cheverud et al., 1992; Kohn et al., 1993; Cocilovo \& Costa-Junquiera, 2001; Rhode \& Arriaza, 2006; and experimental work on rats, Puciarelli, 1978). Kohn et al. (1993) have produced a useful geometric model of the effects of ACM on the cranial base and face and the way in which they interact. The neurocranium is represented by a square and the face by an attached triangle (when viewing the cranium superiorly). The extent of this interdependence between different cranial elements is a matter of controversy which metric studies have attempted to address (Antón, 1989).

Several such studies have been undertaken (e.g. Blackwood \& Danby, 1955; McNeill \& Newton, 1965; Schendel et al., 1980; Brown, 1981; Antón, 1989; Cheverud et al. 1992; Kohn et al., 1993; Cocilovo \& Costa-Junqueira, 2001; Rhode \& Arriaza, 2006) but the number of populations analysed is small and several studies include material from the same collections. Comparisons between studies are limited by the variety of techniques used, which include finite element scaling analysis (Cheverud et al., 1992; Kohn et al., 1993), and measurements taken from the crania directly and/or X-rays (e.g. Moss, 1958; McNeill \& Newton, 1965; Antón, 1989). However, these studies have generally confirmed and quantified the visually observed effects of ACM, and highlighted changes in the shape of the cranial base and face, although the precise differences observed and their extent even within modification types 
vary between studies. It is argued here that this may relate to interpopulation differences in the modification process, even where apparently similar types of modification are performed.

\section{Materials and methods}

The crania studied are derived from four sites in north-central Peru (Figure 1). Pitakilla, Paucarmás and Tuquillo are located on an approximate transect from the Andes to the coast. The sample from Huallamarca represents another coastal population, from Lima.

Pitakilla occupies a long natural rock shelter overlooking the archaeological site of Gotushjirka, at about $3650 \mathrm{~m}$ altitude in the Cordillera Blanca. The crania were from 10 machayes (communal mortuary structures) of which only one remains standing, and a natural tunnel and crevice in the rock shelter. All were lying on the surface. The site dates to the Early Intermediate Period (AD 200-600) and Middle Horizon (AD 600-1100) (Herrera, 2005).

The necropolis at Paucarmás is located on the southern margin of the upper Río Loco in the Cordillera Negra at about $3375 \mathrm{~m}$ altitude. It consists of at least 22 machayes distributed along a horizontal kilometre of slope. The crania studied were from two subterranean structures located beneath large rock outcrops. The human bones lay on the surface within the structures and probably date from the Late Intermediate Period (AD 1100-1400) (Herrera, 2005). Crania were studied on site at both Pitakilla and Paucarmás.

The Tuquillo sample is from a heavily looted Late Intermediate Period cemetery on the Tuquillo peninsula, north of the Huarmey valley. The sample, Registry Number 20040, is from a surface collection conducted by Lorenzo Samaniego in July 1978. There is no published information on the collection (which is stored at the Max Uhle Museum at Sechin, near Casma).

The fourth sample was from the buaca at Huallamarca, situated in the San Isidro district of Lima. This ceremonial adobe platform dates to the Lima culture (AD 200-600), but was used in later periods for burials. The sample consists of eight specimens excavated at the buaca, dating to the Late Intermediate Period and Late Horizon (AD 1400-1532).

\section{Classification of crania}

There are many different classification systems for ACM. Many use broad categories, contrasting 'fronto-occipital deformation' (Cheverud et al., 1992; Clark et al., 2007) or 'antero-posterior deformation' (McNeill \& Newton, 1965; Antón, 1989; Rhode \& Arriaza, 2006) with 'circumferential deformation', or 'vertical' versus 'oblique' occipital orientation (Moss, 1958). However, such systems may mask interpopulation variability in cranial form. Although some researchers avoid (Allison et al. 1981) or discourage (Blackwood \& Danby, 1955) naming types, it is useful to facilitate discussion.

Three types of ACM were recorded in this study. The first, 'posterior flattening', is characterised visually by flattening of the occipital region and an increase in breadth in the parietal region, while the frontal bone is unaffected (Figure 2a). Posterior flattening in our sample may have been unintentional, as it was highly variable in extent, and frequently mild and asymmetrical. This would be consistent with the effects of cradle practices (Neumann, 1942). This type has received little attention in craniometric studies (except Ewing, 1950; Moss, 1958). Antón (1989) suggests that generally this type of modification is not included within ACM, but it is included here because it is the product of cultural practices with potentially intentional effects (Dingwall, 1931), and may have implications for studies attempting to examine relationships between populations using standard craniometric techniques. Reichlen (1982) suggests that posterior flattening was unknown in the Peruvian highlands before the Inca period, but the sample studied here does not support this.

The second group was termed 'bilobed' (e.g. Dingwall, 1931), referring to the two distinct lobes formed in the parietal region on either side of the sagittal suture (Figure 2b). This was clearly distinguished from posterior flattening by the presence of frontal modification and a clear depression along the line of the sagittal suture. Growth is restricted antero-posteriorly and 


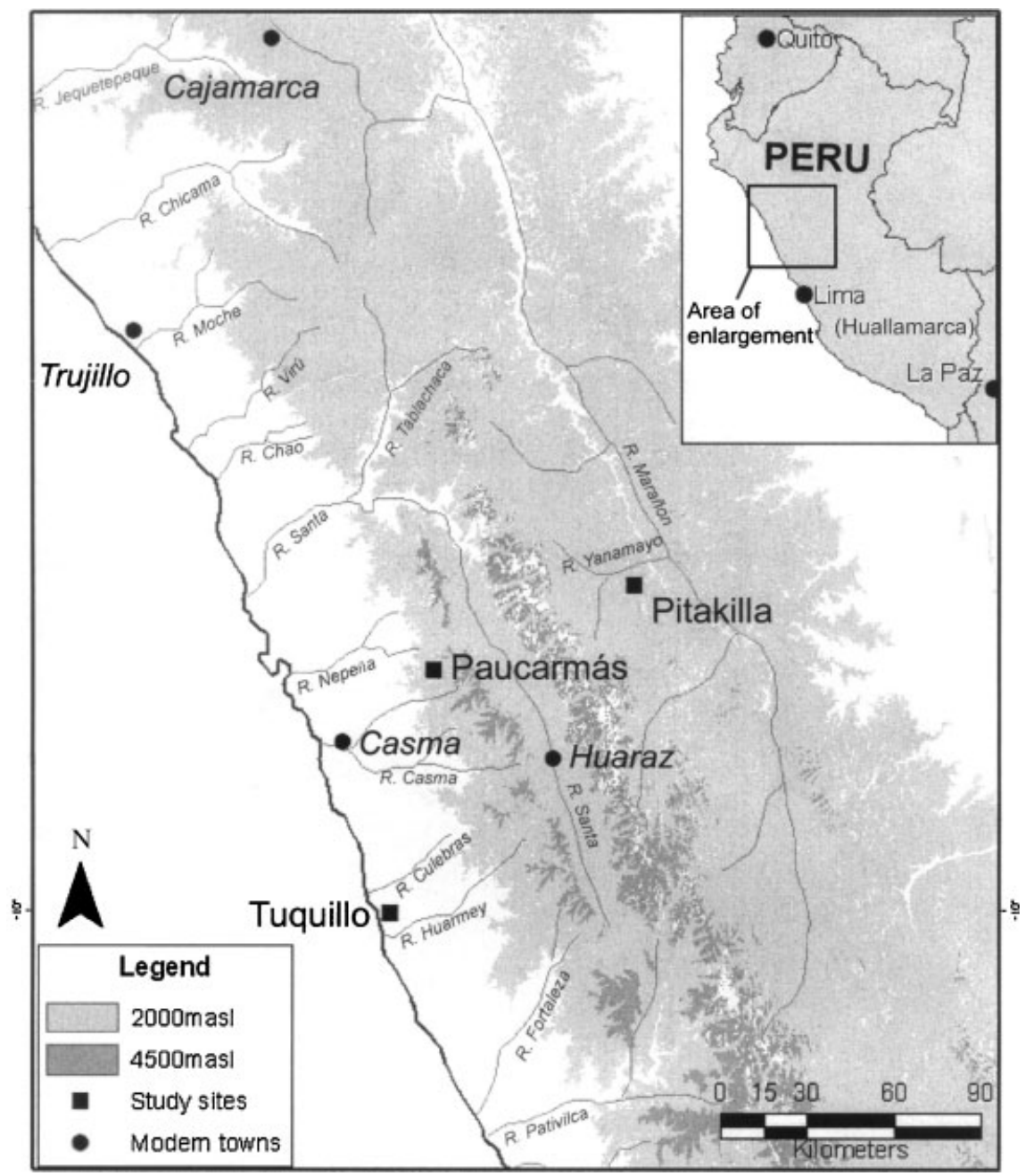

Figure 1. Map of north-central Peru.

compensatory growth occurs laterally and vertically. The direction of restriction is similar to the posterior flattening type, but more marked and affects the frontal bone as well as the occipital. Some cases in the literature (e.g. Dingwall, 1931) are far more marked than any studied here implying substantial interpopulation variation. This type of modification was often found in coastal populations in pre-Columbian Peru (Dingwall, 1931; Bjork \& Bjork, 1965; Reichlen, 1982) and was probably produced using a headdress encircling the vault with an additional band along the line of the sagittal suture (Weiss, 1961; Allison et al., 1981). Although a depression along the sagittal suture may occur naturally, its extent, combination with frontal modification and the geographical limitation of this character to individuals from a single site (Tuquillo) indicate that this is a consequence of this particular method of ACM. Variability in bilobed modification was high in terms of modification of the frontal, angulation of the occipital, and severity (as illustrated in Figure 2b). The occurrence of these different features showed no consistent pattern, so they were studied as a single group.

The third group was termed 'circumferential' and characterised by narrowing and posterosuperior elongation of the cranial vault as a result 


\section{(a)}

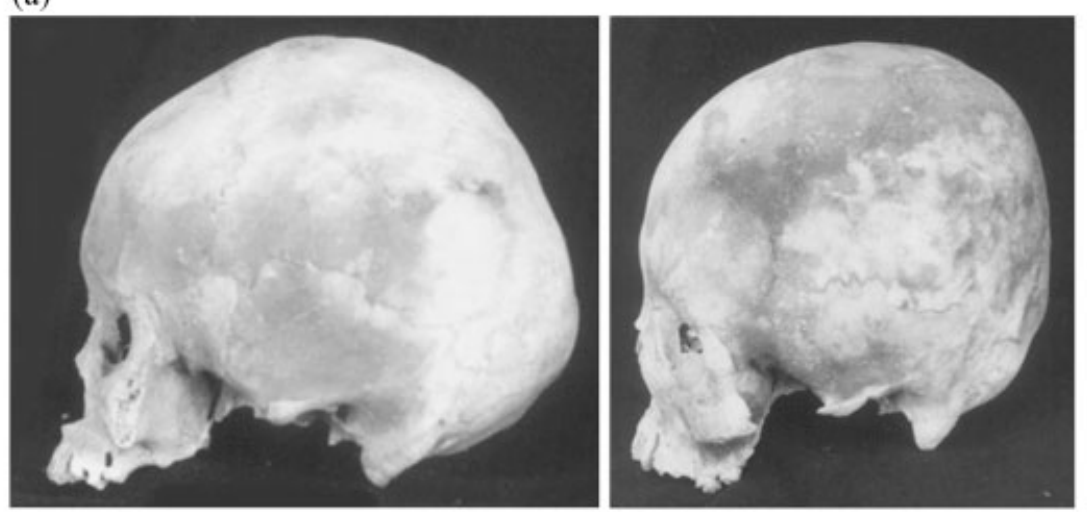

(b)
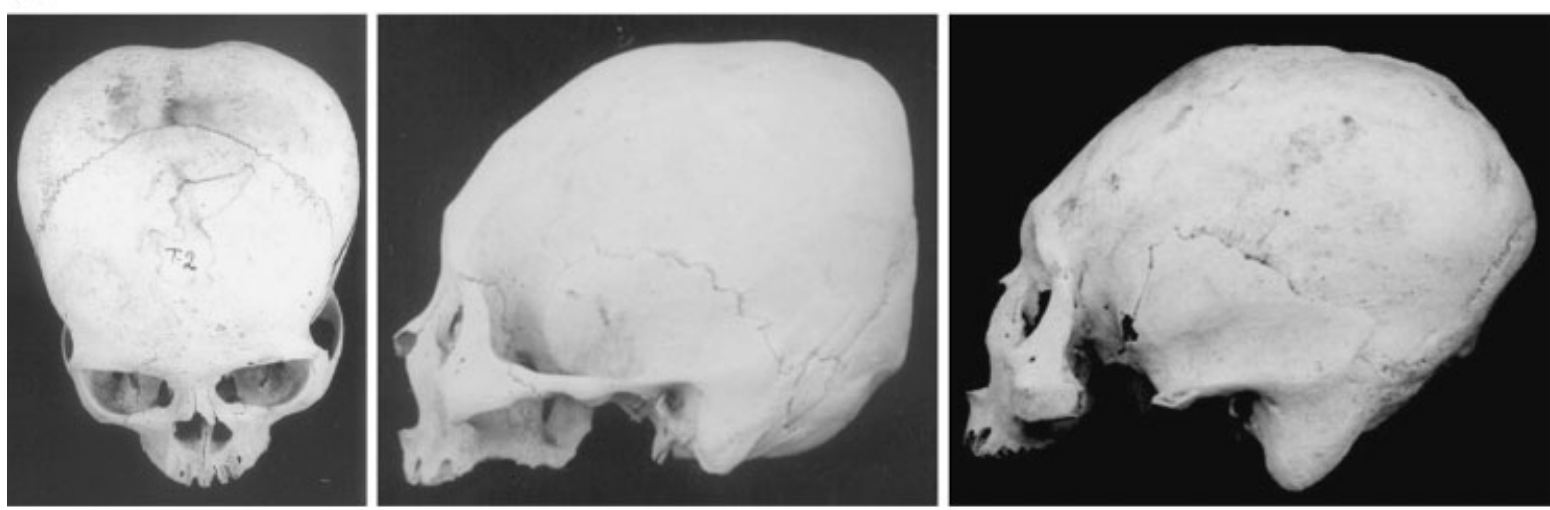

(c)
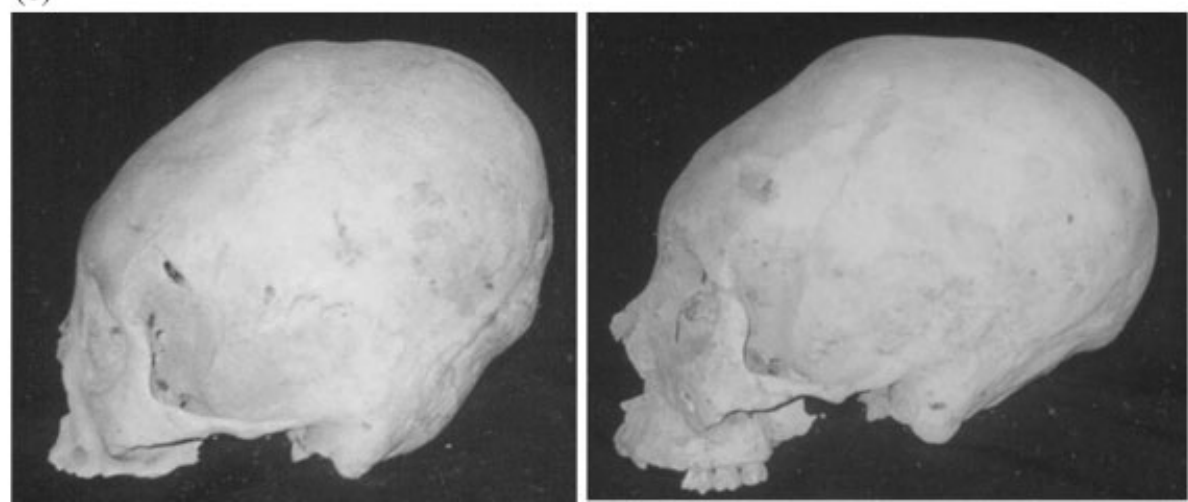

Figure 2. Categories of artificial cranial modification, demonstrating variability in resulting cranial shape within the samples: (a) posterior flattening, (b) bilobed and (c) circumferential.

of binding the cranium around its circumference with fabric or other material (Figure 2c). In preColumbian Peru this type of modification was often (though not exclusively) found in highland populations (Dingwall, 1931; Bjork \& Bjork, 1964; Hoshower et al., 1995). Again, there is consider-

Copyright (C) 2009 John Wiley \& Sons, Ltd. able interpopulation variability in the severity of modification, and resulting cranial shape within (Figure 2c) and between populations (see e.g. Weiss, 1961).

The unmodified group consisted of crania with no indications of ACM. The use of comparative

Int. J. Osteoarchaeol. 20: 317-334 (2010) 
samples from populations other than that from which modified crania are derived has been criticised (Cheverud et al., 1992; Kohn et al., 1993). Although it would be ideal to use crania derived from single populations to minimise the effects of interpopulation genetic or environmental differences, this was not possible due to small sample sizes. Hence unmodified crania from all sites were pooled to produce a single unmodified group.

Current understanding of temporal and geographical craniometric variation in Peru is somewhat limited due to the small number of previous studies (Ross et al., 2008), perhaps in part because ACM is relatively common in Peruvian populations. A recent study of coastal and highland populations from central and northern Peru has demonstrated some differences in cranial shape, but not overall size, between populations (Ross et al., 2008). Coastal populations are characterised by lower, longer cranial vaults than highland populations (Newman, 1943; Ross et al., 2008) and postcranial morphology also shows a distinction between highland and coastal populations (Weinstein, 2005), while there is morphological similarity within these regions even over relatively large areas. This may reflect the combined effects of genetic drift, environmental adaptation (particularly for postcranial morphology) and dietary influences. However, Ericksen (1962) observed a temporal reduction in cranial length in a highland population from Cajamarca which might have been a reflection of increased gene flow with the coast over time. This may be of particular relevance to the populations examined in the current study which were mainly fairly late in date. Archaeological evidence for the degree of interaction between coastal and highland popu- lations is controversial (Weinstein, 2005) but suggests some cultural interaction (and perhaps potentially gene flow) between the coast and the highlands in north-central Peru at this time, probably through trade networks for ceramics and animals/animal products (Lane, 2007). Thus while the use of a combined unmodified sample in this study is not ideal, it seems that the degree of morphological similarity between populations, particularly within the highlands or coast respectively, and evidence suggestive of a degree of gene flow between these regions, justifies the use of a mixed unmodified sample in this case.

Table 1 shows the number of crania in each group and the sites from which they derive. It should be noted that sample sizes are small, particularly for the circumferential group, and varied for individual measurements due to varying preservation. This should be borne in mind when examining the results presented here.

\section{Measurements}

Forty-four measurements were taken, as defined by Howells (1973) and one of the authors (MML), 11 cranial angles (after Howells, 1973) and six indices (after Bass, 1995) were calculated from the measurements. Sex was determined on the basis of cranial morphology (since associated pelves were available only at Huallamarca) using standard methods (Bass, 1995; White \& Folkens, 2000), with final sex determination classified as male, female or indeterminate. To ensure that the sex distribution was not statistically significant between the different groups, a Fisher's exact test

Table 1. Sample sizes and origin

\begin{tabular}{lcccrr}
\hline Group & \multicolumn{3}{c}{ Number of crania } \\
\cline { 2 - 6 } & Pitakilla & Paucarmás & Tuquillo & Huallamarca & Total \\
\hline Unmodified & 11 & 13 & 14 & 8 & 46 \\
Posterior flattening & 32 & 0 & 1 & 0 & 0 \\
Bilobed & 0 & 11 & 0 & 0 & 19 \\
Circumferential & 0 & 24 & 34 & 8 & 109 \\
Total & 43 & & 0 & & 109 \\
\hline
\end{tabular}


was performed (due to small expected values in four cells) which indicated no significant difference $(p=0.108)(\text { Table } 2)^{1}$. Age was estimated on the basis of third molar eruption (where present) and fusion of the spheno-occipital synchondrosis, in order to ensure that only adult crania were included in the study (Bass, 1995; White \& Folkens, 2000).

\section{Analysis of the metric effects of artificial cranial modification}

Means of all measurements, angles and indices were tested for significant differences between the four groups using one-way ANOVA in SPSS 11.0. For measurements showing significant differences between the groups, post boc tests were used to determine which differences were significant between the unmodified and each of the artificially modified groups, and between the different forms of ACM, in order clarify the pattern of differences. Where the Levine statistic for equality of variances was insignificant (and equal variances could be assumed), the post boc test used was Hochberg's GT2 test, while where it was significant, a Games-Howell test was used (Field, 2005).

Canonical variates analysis (CVA, or discriminant analysis) was used to explore how well the different types of ACM could be distinguished metrically from each other and from unmodified crania, which measurements are principally responsible for the differences observed; and whether the variation in the cranial vault associated with different forms of modification influenced facial morphology. In canonical variates analysis, multiple variables can be combined to produce mathematical equations (functions) which separate the groups most effectively (Klecka, 1980). Variables to be included in the analysis were selected from those giving significant differences

\footnotetext{
${ }^{1} \mathrm{~A}$ female bias is apparent in three of the four groups. In the groups showing ACM this may relate to the effects of ACM influencing the appearance of sexually dimorphic traits traditionally used to estimate sex. It was due to the uncertain reliability of sex estimates based only on the cranium in individuals showing ACM that sex was not factored into the analysis.
}

Copyright (C) 2009 John Wiley \& Sons, Ltd.
Table 2. Sex of individuals by ACM type

\begin{tabular}{lrcrr}
\hline & Male & Female & Indet. & Total \\
\hline Unmodified & 16 & 27 & 3 & 46 \\
Occipital flattening & 14 & 12 & 7 & 33 \\
Bilobed & 3 & 14 & 2 & 19 \\
Circumferential & 3 & 6 & 2 & 11 \\
Total & 36 & 59 & 14 & 109 \\
\hline
\end{tabular}

in the ANOVA results, and sample size was also taken into consideration to maximise the number of specimens included.

Clark et al. (2007) recently applied discriminant analysis to craniometric data from artificially modified samples in order to develop a general equation to assist in distinguishing artificially modified and unmodified crania. Their focus was therefore on common features of different types of ACM, specifically cranial shape in the sagittal plane, in order to achieve maximum separation of modified and unmodified crania. In contrast, in the present study we applied similar techniques as a means to investigate the major differences between modification types using a variety of both cranial and facial measurements.

\section{Results}

Table 1 above detailed the sample sizes and origin of crania studied. A total of 46 crania were classified as unmodified, 33 as showing posterior flattening, 19 were classified as bilobed and 11 as showing circumferential modification. It should be noted that sample sizes for individual measurements vary due to differential preservation. The results of the ANOVA tests are given in Table 3, along with descriptions of the measurements taken and abbreviations used to refer to them. The results of the post hoc pairwise comparisons between groups are given in Tables 4-9.

The results confirm the observation that the major effects of ACM are on the cranial vault, as indicated by the highly significant differences between unmodified and artificially modified crania in measurements of cranial length (GOL, NOL) and breadth (XFB, XPB, AUB, ASB, STB), angles of the vault (FRA, PAA, OCA) and indices of cranial shape.

Int. J. Osteoarchaeol. 20: 317-334 (2010) 
This analysis also allows quantification of the observed effects of ACM. The posteriorly flattened sample has significantly shorter vaults than the unmodified sample (GOL is reduced by $4.7 \%$, NOL by $4.9 \%)$. The breadth (XPB) is greater by $4.9 \%$. Whilst frontal and occipital angles are unaffected, the parietal angle in posteriorly flattened crania is more acute. Bilobed modification also results in shortened vaults (GOL and NOL are reduced by $7.5 \%$ and $7.0 \%$ respectively) and increased breadth (11.2\% greater XPB) relative to the unmodified sample. By contrast, circumferential modification exhibits significantly greater cranial length (NOL) by $4.2 \%$, and a $5.5 \%$ lower breadth (XPB) compared with the unmodified group, and significantly longer frontal and occipital cords (FRC, OCC) and frontal flattening (FRA). Surprisingly, no significant difference in GOL was seen between these samples.

ACM also affects the morphology of the cranial vault in less visually obvious ways. With posterior flattening, greater cranial breadth was also observed in the frontal (XFB, STB) and temporal (AUB) areas. The difference in vault breadth is greater closer to the source of growth restriction (i.e. in the posterior region) than anteriorly (frontal region). Similarly, bilobed modification shows a significantly higher average maximum frontal breadth (XFB), and greater breadth in the temporal region. Since it is thought that bilobed modification is effected by applying pressure to the frontal and posterior regions of the neurocranium, it is interesting that this effect is so much less than on the parietal breadth. Pressure may be greatest on the posterior part of the cranium, or it may be more plastic (being less constrained by facial development) allowing more compensatory growth in this region.

The results also imply that in posteriorly flattened and bilobed crania, the majority of compensatory growth in the neurocranium occurs in the mediolateral plane rather than in a supero-inferior direction. There are no significant differences in cranial height $(\mathrm{BBH})$ between unmodified and posteriorly flattened or bilobed crania, yet they show highly significant differences from unmodified crania in cranial breadth across the parietals, frontal and temporals. Although the modifying apparatus which is suggested to produce bilobed modification (see
Weiss, 1961; Allison et al., 1981) might restrict height growth along the sagittal suture and frontal; no such height-restrictive effects should exist for the posteriorly flattened crania. It is possible that there is an increase in height which is not reflected in the measurement taken (basibregmatic height, $\mathrm{BBH}$ ), since the work of Antón (1989) and McNeill \& Newton (1965) on 'anteroposterior' modification imply that there is height increase mainly posterior to bregma. Alternatively, small sample size due to frequent damage to the cranial base may have prevented differences from attaining statistical significance between the groups.

Unexpectedly, circumferential modification also showed no significant difference in cranial height. However, the visually marked height increase is principally posterior to the point of measurement, which may account for this result. Small sample size may also contribute.

Comparisons of different types of ACM highlight the contrasts described above in the direction of restriction and lateral growth between the posteriorly flattened and bilobed crania on the one hand, and the circumferentially modified crania on the other. The suggestion that the effects of posterior flattening are less severe than bilobed modification is supported, with the former showing a smaller decrease in cranial length and a smaller increase in cranial breadth across the parietals, frontal and temporals. However, the differences in the effects on breadth were only statistically significant between these groups for parietal breadth. Bilobed modification shows significantly greater frontal and occipital flattening in the sagittal plane compared with posterior flattening, again reflecting the greater severity of modification in the bilobed group and differences in the method used to produce the modification.

Only bilobed modification shows significant differences from unmodified crania in facial morphology, namely a significantly higher mean fronto-maxillary breadth (FMB) and less prognathism (indicated by SSS). The posteriorly flattened group shows significantly greater facial flatness in the orbital area (DKA) than the bilobed group, and the posteriorly flattened greater than the circumferential group. The circumferential group shows significantly greater lower-facial flatness than the bilobed group. 
Table 3. Descriptions of and ANOVA results for all measurements taken, statistically significant differences ( $p \leq 0.05)$ indicated in italics

\begin{tabular}{|c|c|c|c|c|c|}
\hline Measurement & Description & Region & $n$ & ANOVA $F$ & $p$ \\
\hline GOL & Maximum vault length from glabella & Vault & 101 & 20.109 & $<0.001$ \\
\hline NOL & Maximum vault length from nasal bridge & Vault & 100 & 26.796 & $<0.001$ \\
\hline BNL & Basion-nasion length & Face & 71 & 0.913 & 0.440 \\
\hline $\mathrm{BBH}$ & Cranial height & Vault & 69 & 2.317 & 0.084 \\
\hline XFB & Anterior breadth of cranial vault & Vault & 103 & 12.743 & $<0.001$ \\
\hline XPB & Maximum cranial vault breadth & Vault & 104 & 44.279 & $<0.001$ \\
\hline ASB & Lower posterior breadth of vault & Vault & 98 & 13.923 & $<0.001$ \\
\hline$A \cup B$ & Vault breadth at ear level & Vault & 98 & 6.207 & 0.001 \\
\hline WCB & Minimum anterior vault breadth & Vault & 86 & 1.074 & 0.365 \\
\hline STB & Anterior vault breadth & Vault & 104 & 17.969 & $<0.001$ \\
\hline ZYB & Breadth of face at cheek bones & Face & 61 & 1.702 & 0.177 \\
\hline $\mathrm{NPH}$ & Upper facial height & Face & 83 & 3.372 & 0.023 \\
\hline $\mathrm{NLH}$ & Height of nasal opening & Face & 89 & 0.610 & 0.610 \\
\hline NLB & Breadth of nasal opening & Face & 88 & 0.561 & 0.643 \\
\hline $\mathrm{OBH}$ & Orbit height & Face & 95 & 2.859 & 0.041 \\
\hline $\mathrm{OBB}$ & Orbit breadth & Face & 95 & 2.193 & 0.094 \\
\hline JUB & Maximum breadth of face at zygomatic arches & Face & 72 & 1.144 & 0.338 \\
\hline MAB & Maximum breadth of palate & Face & 79 & 0.741 & 0.531 \\
\hline $\mathrm{MDH}$ & Height of mastoid process & Base & 92 & 2.334 & 0.079 \\
\hline MDB & Breadth of mastoid process & Base & 96 & 0.130 & 0.942 \\
\hline WNB & Minimum breadth of nasal bridge & Face & 96 & 2.456 & 0.068 \\
\hline IML & Inferior length of cheek & Face & 78 & 0.435 & 0.728 \\
\hline XML & Maximum length of cheek & Face & 78 & 0.672 & 0.572 \\
\hline WMH & Cheek height & Face & 91 & 2.979 & 0.036 \\
\hline BPL & Facial depth & Face & 64 & 0.515 & 0.674 \\
\hline FOL & Length of foramen magnum & Base & 68 & 2.238 & 0.092 \\
\hline $\mathrm{FOB}$ & Breadth of foramen magnum & Base & 82 & 3.059 & 0.033 \\
\hline ZMB & Midfacial breadth & Face & 80 & 1.695 & 0.175 \\
\hline SSS & Facial projection below nose & Face & 63 & 4.528 & 0.006 \\
\hline FMB & Facial breadth in orbital region (upper) & Face & 99 & 3.875 & 0.012 \\
\hline NAS & Facial flatness in upper orbital region & Face & 98 & 0.940 & 0.424 \\
\hline EKB & Facial breadth in orbital region (lower) & Face & 85 & 1.252 & 0.296 \\
\hline DKS & Facial flatness in lower orbital region & Face & 85 & 6.213 & 0.001 \\
\hline SOS & Supraorbital projection & Face & 106 & 2.294 & 0.082 \\
\hline GLS & Projection of glabella & Face & 107 & 1.813 & 0.149 \\
\hline FRC & Antero-posterior cord of frontal bone & Vault & 107 & 15.555 & $<0.001$ \\
\hline FRS & $\begin{array}{l}\text { Frontal subtense, reflects curvature of frontal } \\
\text { bone in antero-posterior direction }\end{array}$ & Vault & 107 & 12.329 & $<0.001$ \\
\hline FRF & $\begin{array}{l}\text { Point of greatest antero-posterior curvature } \\
\text { of frontal }\end{array}$ & Vault & 107 & 3.641 & 0.015 \\
\hline PAC & Antero-posterior cord of parietals & Vault & 101 & 15.673 & $<0.001$ \\
\hline PAS & $\begin{array}{l}\text { Parietal subtense, reflects curvature of parietal } \\
\text { in antero-posterio direction }\end{array}$ & Vault & 101 & 1.759 & 0.160 \\
\hline PAF & $\begin{array}{l}\text { Point of greatest antero-posterior curvature of } \\
\text { parietal }\end{array}$ & Vault & 101 & 0.983 & 0.404 \\
\hline OCC & Antero-posterior cord of parietals & Vault & 90 & 5.844 & 0.001 \\
\hline OCS & $\begin{array}{l}\text { Occipital subtense, reflects curvature of occipital } \\
\text { in antero-posterior direction }\end{array}$ & Vault & 89 & 7.565 & $<0.001$ \\
\hline OCF & $\begin{array}{l}\text { Point of maximum antero-posterior curvature of } \\
\text { occipital }\end{array}$ & Vault & 89 & 0.729 & 0.538 \\
\hline FRA & Antero-posterior angulation of frontal & Vault & 107 & 14.141 & $<0.001$ \\
\hline PAA & Antero-posterior angulation of parietals & Vault & 101 & 10.572 & $<0.001$ \\
\hline OCA & Antero-posterior angulation of occipital & Vault & 89 & 7.660 & $<0.001$ \\
\hline NAA & Angle at nasion in relation to basion and prosthion & Face/Base & 63 & 0.580 & 0.631 \\
\hline PRA & Angle at prosthion in relation to basion and nasion & Face/Base & 63 & 0.970 & 0.413 \\
\hline BAA & Angle at basion in relation to nasion and prosthion & Face/Base & 63 & 5.783 & 0.002 \\
\hline NBA & Angle at nasion in relation to basion and bregma & Face/Base & 92 & 10.658 & $<0.001$ \\
\hline BBA & Angle at basion in relation to nasion and bregma & Face/Base & 70 & 0.024 & 0.995 \\
\hline
\end{tabular}


Table 3. (Continued)

\begin{tabular}{|c|c|c|c|c|c|}
\hline Measurement & Description & Region & $n$ & ANOVA $F$ & $p$ \\
\hline SSA & $\begin{array}{l}\text { Zygomaxillary angle, facial flatness at level of base } \\
\text { of nose }\end{array}$ & Face & 65 & 4.042 & 0.011 \\
\hline NFA & Angle between nasal bridge and orbital margins & Face & 101 & 0.109 & 0.955 \\
\hline DKA & $\begin{array}{l}\text { Dacryal angle, relative sweeping back of orbital } \\
\text { margins relative to midface }\end{array}$ & Face & 85 & 6.494 & 0.001 \\
\hline Cranial index & $\mathrm{XPB} / \mathrm{GOL} \times 100$ & Vault & 101 & 58.044 & $<0.001$ \\
\hline Cranial module & $(\mathrm{GOL}+\mathrm{XPB}+\mathrm{BBH}) / 3$ & Vault & 68 & 1.711 & 0.174 \\
\hline $\begin{array}{l}\text { Cranial length- } \\
\text { height index }\end{array}$ & $\mathrm{BBH} / \mathrm{GOL} \times 100$ & Vault & 68 & 7.3860 & $<0.001$ \\
\hline Cranial breadth- & $\mathrm{BBH} / \mathrm{XPB} \times 100$ & Vault & 69 & 37.420 & $<0.001$ \\
\hline Mean height index & $(\mathrm{BBH} \times 100) /([\mathrm{GOL}+\mathrm{XPB}] / 2)$ & Face & 68 & 4.518 & 0.0068 \\
\hline Upper facial index & $\mathrm{NPH} / \mathrm{ZMB} \times 100$ & Face & 73 & 1.134 & 0.342 \\
\hline
\end{tabular}

Although the one-way ANOVA demonstrates statistically significant differences in mean upper facial height (NPH) and orbital height $(\mathrm{OBH})$ between all of the groups, post boc tests fail to show any significant pairwise differences.

\section{Canonical variates analysis (discriminant analysis)}

The function giving the highest rate of accurate classification used nine measurements: NOL, $\mathrm{XFB}, \mathrm{XPB}, \mathrm{ASB}, \mathrm{AUB}, \mathrm{STB}, \mathrm{PAC}, \mathrm{FRC}, \mathrm{OCS}_{\text {; }}$ and two angles: FRA and PAA. The functions can be used to predict group membership based on these variables, which can be compared with the actual group membership to indicate the effectiveness of the model. The number of specimens classified mathematically into the categories identified visually was $91.3 \%$, or $73 / 80$. This is considerably higher than expected if specimens were randomly assigned to groups, suggesting that the functions are powerful, and that the visual differences between the samples are quantitatively expressed by the measurements taken.

The first function is primarily responsible for the separation of the circumferential group from others, while the second function separates the bilobed group from the unmodified and posterior flattening groups (Figure 3). The circumferential group is visually well separated from the other three groups in Figure 3, and while the

Table 4. Pairwise comparisons: unmodified and posterior flattening

\begin{tabular}{lrrrrrr}
\hline Measurement & \multicolumn{2}{c}{ Unmodified } & & \multicolumn{2}{c}{ Posterior flattening } & \multicolumn{2}{c}{$\begin{array}{c}\text { Significance of } \\
\text { post hoc test }(p)\end{array}$} \\
\cline { 2 - 3 } & Mean & SD & & Mean & SD & \\
\hline GOL & 168.62 & 6.243 & 160.39 & 8.276 & $<0.001$ \\
NOL & 167.51 & 5.703 & 159.13 & 7.010 & $<0.001$ \\
XFB & 113.45 & 4.163 & 117.94 & 5.074 & 0.001 \\
XPB & 137.17 & 5.938 & 143.76 & 5.368 & $<.001$ \\
AUB & 123.72 & 5.306 & 127.19 & 4.806 & 0.029 \\
STB & 110.86 & 5.493 & 115.76 & 5.068 & 0.002 \\
FRF & 49.77 & 5.043 & 53.27 & 5.101 & 0.020 \\
PAC & 104.30 & 5.983 & 100.33 & 6.859 & 0.027 \\
PAA & 132.08 & 3.543 & 127.92 & 3.337 & $<.001$ \\
NBA & 80.88 & 4.359 & 84.21 & 3.649 & 0.008 \\
Cranial index & 81.47 & 4.468 & 89.89 & 6.153 & $<0.001$ \\
Cranial length-height index & 77.31 & 4.174 & 81.56 & 3.746 & 0.016 \\
\hline
\end{tabular}


Table 5. Pairwise comparisons: unmodified and bilobed

\begin{tabular}{|c|c|c|c|c|c|}
\hline \multirow[t]{2}{*}{ Measurement } & \multicolumn{2}{|c|}{ Unmodified } & \multicolumn{2}{|c|}{ Bilobed } & \multirow{2}{*}{$\begin{array}{l}\text { Significance of } \\
\text { post hoc test }(p)\end{array}$} \\
\hline & Mean & SD & Mean & $\mathrm{SD}$ & \\
\hline GOL & 168.62 & 6.243 & 155.68 & 8.374 & $<0.001$ \\
\hline NOL & 167.51 & 5.703 & 155.58 & 7.967 & $<0.001$ \\
\hline XFB & 113.45 & 4.163 & 120.11 & 5.527 & $<0.001$ \\
\hline XPB & 137.17 & 5.938 & 152.32 & 6.733 & $<0.001$ \\
\hline$A \cup B$ & 123.72 & 5.306 & 128.21 & 4.768 & 0.011 \\
\hline STB & 110.86 & 5.493 & 117.05 & 7.457 & 0.001 \\
\hline SSS & 22.90 & 3.059 & 25.39 & 2.973 & 0.028 \\
\hline$D K S$ & 7.84 & 2.167 & 9.44 & 1.822 & 0.057 \\
\hline FMB & 97.29 & 4.805 & 100.79 & 4.697 & 0.027 \\
\hline FRS & 21.52 & 2.435 & 18.05 & 2.990 & 0.001 \\
\hline PAC & 104.30 & 4.983 & 93.26 & 5.173 & $<0.001$ \\
\hline OCS & 24.64 & 3.462 & 19.47 & 2.932 & $<0.001$ \\
\hline FRA & 135.59 & 4.695 & 141.42 & 4.509 & $<0.001$ \\
\hline PAA & 132.08 & 3.543 & 125.73 & 6.312 & 0.001 \\
\hline OCA & 124.28 & 6.290 & 133.53 & 5.652 & $<0.001$ \\
\hline SSA & 129.04 & 6.127 & 120.96 & 16.853 & 0.057 \\
\hline Cranial index & 81.47 & 4.468 & 98.09 & 6.655 & $<0.001$ \\
\hline Cranial length-height index & 77.31 & 4.174 & 81.37 & 4.111 & 0.006 \\
\hline Cranial breadth-height index & 93.87 & 4.479 & 83.15 & 1.036 & $<0.001$ \\
\hline
\end{tabular}

Italics denote comparisons which are close to showing statistically significant differences between the groups.

unmodified and bilobed groups are well separated from each other, the posterior flattening group overlaps both of these groups. This suggests that the circumferentially modified sample is the most morphologically distinct.

The Wilks' $\lambda$ values and their significances indicate that all three functions are likely to make substantial contribution to the separation of the groups ( $p$ values before derivation of first 2 functions $<0.001$, before derivation of Function
$3=0.025)$. The canonical correlations indicate that particularly the first and second functions show high levels of correlation with the groups, and hence are powerful discriminators between them. Function 1 has an eigenvalue of 2.939, a canonical correlation of 0.864 and accounts for $59.4 \%$ of the variance. Function 2 accounts for $34.4 \%$ of the variance, with an eigenvalue of 1.704 and a canonical correlation of 0.794 , while Function 3 accounts for $6.1 \%$ of the variance

Table 6. Pairwise comparisons: unmodified and circumferential

\begin{tabular}{|c|c|c|c|c|c|}
\hline \multirow[t]{2}{*}{ Measurement } & \multicolumn{2}{|c|}{ Unmodified } & \multicolumn{2}{|c|}{ Circumferential } & \multirow{2}{*}{$\begin{array}{l}\text { Significance of } \\
\text { post hoc test }(p)\end{array}$} \\
\hline & Mean & SD & Mean & SD & \\
\hline NOL & 167.51 & 5.703 & 174.30 & 6.567 & 0.030 \\
\hline XPB & 137.17 & 5.938 & 129.60 & 5.502 & 0.002 \\
\hline ASB & 108.98 & 4.092 & 100.50 & 4.720 & $<0.001$ \\
\hline STB & 110.86 & 5.493 & 102.90 & 4.999 & 0.001 \\
\hline FRC & 106.25 & 4.696 & 116.64 & 4.105 & $<0.001$ \\
\hline FRS & 21.52 & 2.435 & 18.00 & 1.183 & $<0.001$ \\
\hline OCC & 95.53 & 5.764 & 102.71 & 6.969 & 0.017 \\
\hline FRA & 135.59 & 4.695 & 144.53 & 2.103 & $<0.001$ \\
\hline BAA & 38.76 & 2.441 & 41.94 & 1.705 & 0.040 \\
\hline Cranial index & 81.47 & 4.468 & 75.20 & 3.722 & 0.010 \\
\hline Cranial breadth-height index & 93.87 & 4.174 & 101.03 & 5.764 & 0.001 \\
\hline
\end{tabular}


Table 7. Pairwise comparisons: posterior flattening and bilobed

\begin{tabular}{|c|c|c|c|c|c|}
\hline \multirow[t]{2}{*}{ Measurement } & \multicolumn{2}{|c|}{ Posterior flattening } & \multicolumn{2}{|c|}{ Bilobed } & \multirow{2}{*}{$\begin{array}{l}\text { Significance of } \\
\text { post hoc test }(p)\end{array}$} \\
\hline & Mean & SD & Mean & SD & \\
\hline XPB & 143.76 & 5.368 & 152.32 & 6.733 & $<0.001$ \\
\hline DKS & 6.73 & 2.414 & 9.44 & 1.822 & 0.001 \\
\hline FRS & 21.45 & 3.011 & 18.05 & 2.990 & $<0.001$ \\
\hline PAC & 100.33 & 6.859 & 93.26 & 5.173 & $<0.001$ \\
\hline OCS & 22.93 & 4.085 & 19.47 & 2.932 & 0.007 \\
\hline FRA & 136.77 & 5.752 & 141.42 & 4.509 & 0.006 \\
\hline OCA & 126.90 & 8.336 & 133.53 & 5.652 & 0.009 \\
\hline NBA & 84.21 & 3.649 & 78.22 & 3.011 & $<0.001$ \\
\hline DKA & 160.74 & 6.745 & 153.39 & 5.024 & 0.001 \\
\hline Cranial index & 89.89 & 6.154 & 98.09 & 6.655 & $<0.001$ \\
\hline Cranial breadth-height index & 90.15 & 3.690 & 83.15 & 4.517 & $<0.001$ \\
\hline
\end{tabular}

(eigenvalue $=0.304$, canonical correlation $=0.483)$. The classification matrices using the original functions give a high rate of correct classification (91.3\%), the main errors occurring in distinguishing between unmodified and posterior flattening cases in line with the impression given by Figure 3 that these two groups are not well separated. The cross-validation procedure (where each case is classified using new functions derived from all other cases except that in question, Table 10) gave a lower rate of correct classification at $73.9 \%$, again reflecting mainly problems distinguishing between unmodified and posterior flattening, and between posterior flattening and bilobed crania. This reflects the overlap between these types in Figure 3 and the broad similarity in the direction of modification forces in posterior flattening and bilobed crania, with the result that more extreme cases of posterior flattening and milder cases of bilobed modification may show metric similarities.

\section{Discussion}

The effects of ACM observed here are broadly consistent with those found in other studies (e.g.

Table 8. Pairwise comparisons: posterior flattening and circumferential

\begin{tabular}{|c|c|c|c|c|c|}
\hline \multirow[t]{2}{*}{ Measurement } & \multicolumn{2}{|c|}{ Posterior flattening } & \multicolumn{2}{|c|}{ Circumferential } & \multirow{2}{*}{$\begin{array}{l}\text { Significance of } \\
\text { post hoc test }(p)\end{array}$} \\
\hline & Mean & SD & Mean & SD & \\
\hline GOL & 160.39 & 8.276 & 172.50 & 6.346 & $<0.001$ \\
\hline NOL & 159.13 & 7.010 & 174.30 & 6.567 & $<0.001$ \\
\hline XFB & 117.94 & 5.074 & 112.00 & 4.796 & 0.003 \\
\hline XPB & 143.76 & 5.368 & 129.60 & 5.502 & $<0.001$ \\
\hline ASB & 110.07 & 4.683 & 100.50 & 4.720 & $<0.001$ \\
\hline$A \cup B$ & 127.19 & 4.806 & 121.89 & 4.986 & 0.038 \\
\hline STB & 115.76 & 5.068 & 102.90 & 4.999 & $<0.001$ \\
\hline DKS & 6.73 & 2.414 & 9.00 & 1.500 & 0.043 \\
\hline FRC & 106.67 & 5.010 & 116.64 & 4.105 & $<0.001$ \\
\hline FRS & 21.45 & 3.011 & 18.00 & 1.183 & 0.002 \\
\hline OCC & 93.50 & 5.438 & 102.71 & 6.969 & 0.001 \\
\hline FRA & 136.77 & 5.752 & 144.53 & 2.103 & $<0.001$ \\
\hline BAA & 38.78 & 1.281 & 41.94 & 1.705 & 0.022 \\
\hline NBA & 84.21 & 3.649 & 78.52 & 4.499 & 0.001 \\
\hline DKA & 160.74 & 6.745 & 153.45 & 4.786 & 0.012 \\
\hline Cranial index & 89.89 & 6.154 & 75.20 & 3.722 & $<0.001$ \\
\hline Cranial length-height index & 81.56 & 3.746 & 76.01 & 2.912 & 0.013 \\
\hline Cranial breadth-height index & 90.15 & 3.690 & 101.03 & 5.764 & $<0.001$ \\
\hline
\end{tabular}


Table 9. Pairwise comparisons: bilobed and circumferential

\begin{tabular}{|c|c|c|c|c|c|}
\hline \multirow[t]{2}{*}{ Measurement } & \multicolumn{2}{|c|}{ Bilobed } & \multicolumn{2}{|c|}{ Circumferential } & \multirow{2}{*}{$\begin{array}{l}\text { Significance of } \\
\text { post hoc test }(p)\end{array}$} \\
\hline & Mean & SD & Mean & SD & \\
\hline GOL & 155.68 & 8.374 & 172.50 & 6.346 & $<0.001$ \\
\hline NOL & 155.58 & 7.967 & 174.30 & 6.567 & $<0.001$ \\
\hline XFB & 120.11 & 5.527 & 112.00 & 4.706 & $<0.001$ \\
\hline XPB & 152.32 & 6.733 & 129.60 & 5.502 & $<0.001$ \\
\hline ASB & 110.28 & 3.893 & 100.50 & 4.720 & $<0.001$ \\
\hline$A \cup B$ & 129.21 & 4.768 & 121.89 & 4.986 & 0.015 \\
\hline STB & 117.05 & 7.457 & 102.90 & 4.999 & $<0.001$ \\
\hline SSS & 25.39 & 2.973 & 21.56 & 2.603 & 0.009 \\
\hline FMB & 100.79 & 4.697 & 95.78 & 3.073 & 0.031 \\
\hline FRC & 105.42 & 5.167 & 116.64 & 4.105 & $<0.001$ \\
\hline OCC & 93.16 & 5.210 & 102.71 & 6.969 & 0.001 \\
\hline SSA & 120.96 & 16.853 & 133.28 & 4.181 & 0.022 \\
\hline Cranial index & 98.09 & 6.655 & 75.20 & 3.722 & $<0.001$ \\
\hline Cranial length-height index & 81.37 & 4.111 & 76.01 & 2.912 & 0.008 \\
\hline Cranial breadth-height index & 83.15 & 4.517 & 101.03 & 5.764 & $<0.001$ \\
\hline Mean height index & 82.16 & 3.307 & 86.70 & 3.331 & 0.010 \\
\hline
\end{tabular}

Blackwood \& Danby, 1955; McNeill \& Newton, 1965; Brown, 1981; Antón, 1989; Cheverud et al., 1992; Kohn et al., 1993; Cocilovo \& Costa-Junqueira, 2001; Rhode \& Arriaza, 2006) but suggest interpopulation differences in the extent and precise pattern of the effects of ACM on the vault. For example, Antón (1989) reported significantly greater maximum cranial breadth by

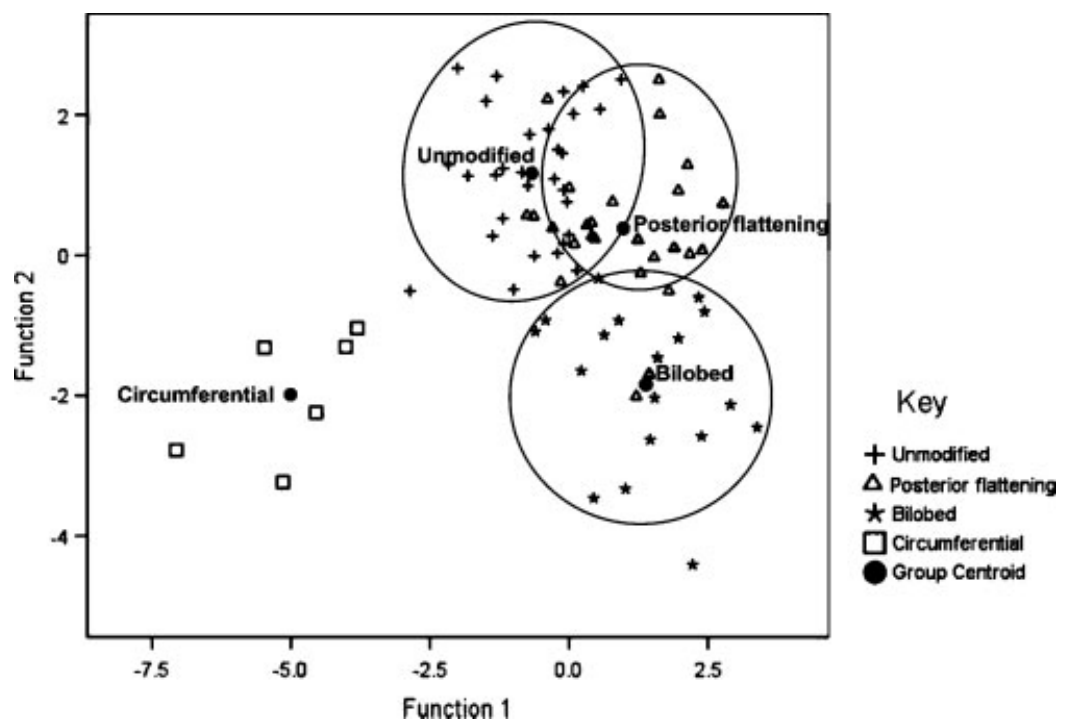

Figure 3. Two-dimensional plot of the first two functions of the canonical variates analysis. NOL (cranial length) makes the greatest contribution to the first discriminant function and is negatively loaded. FRC and FRA (both characters of the frontal) are the other major negatively-loaded contributors, while AUB, XFB, XPB (all cranial breadths), OCS, ASB and PAC are positively loaded (in order of decreasing importance). In the second function, PAA (parietal angle, positively loaded) and XPB (parietal breadth, negatively loaded) make the highest, and approximately equal, contributions. AUB, PAC and STB are the other main positively loaded variables, while FRA and FRC represent the other main negatively loaded variables in function 2. In the third function (not represented in the graph), the most important variables are NOL and XPB (both negatively loaded), with FRC and AUB (both positively loaded) also making important contributions. 
Table 10. Classification matrix showing the initial and cross-validated classifications of cases based on the discriminant functions calculated from the selected variables

\begin{tabular}{|c|c|c|c|c|c|c|c|}
\hline & & \multirow[t]{2}{*}{ Original group } & \multicolumn{4}{|c|}{ Predicted group membership } & \multirow[t]{2}{*}{ Total } \\
\hline & & & Unmodified & Posterior flattening & Bilobed & Circumferential & \\
\hline \multirow[t]{8}{*}{ Original functions } & \multirow[t]{4}{*}{$n$} & Unmodified & 29 & 1 & 0 & 0 & 30 \\
\hline & & Posterior flattening & 3 & 21 & 2 & 0 & 26 \\
\hline & & Bilobed & 0 & 1 & 17 & 0 & 18 \\
\hline & & Circumferential & 0 & 0 & 0 & 6 & 6 \\
\hline & \multirow{4}{*}{$\%$} & Unmodified & 96.7 & 3.3 & 0 & 0 & 100.0 \\
\hline & & Posterior flattening & 11.5 & 80.8 & 7.7 & 0 & 100.0 \\
\hline & & Bilobed & 0 & 5.6 & 94.4 & 0 & 100.0 \\
\hline & & Circumferential & 0 & 0 & 0 & 100.0 & 100.0 \\
\hline \multirow[t]{7}{*}{ Cross-validation } & \multirow[t]{4}{*}{$n$} & Unmodified & 27 & 2 & 0 & 1 & 30 \\
\hline & & Posterior flattening & 9 & 13 & 4 & 0 & 26 \\
\hline & & Bilobed & 3 & 2 & 13 & 0 & 18 \\
\hline & & Circumferential & 0 & 0 & 0 & 6 & 6 \\
\hline & \multirow[t]{3}{*}{$\%$} & Unmodified & 90.0 & 6.7 & 0 & 3.3 & 100.0 \\
\hline & & Posterior flattening & $\begin{array}{l}34.6 \\
167\end{array}$ & 50.0 & 15.4 & 0 & 100.0 \\
\hline & & $\begin{array}{l}\text { Bllobed } \\
\text { Circumferential }\end{array}$ & $\begin{array}{c}10.1 \\
0\end{array}$ & 0 & $\begin{array}{c}2.2 \\
0\end{array}$ & 100.0 & 100.0 \\
\hline
\end{tabular}

In the cross validation analysis, each case is classified using functions derived from all other cases excluding the case in question. In the original analysis, $91.3 \%$ of cases were correctly classified, while in the cross-validation analysis $73.8 \%$ of cases were correctly classified. This decrease relates principally to difficulties distinguishing between the unmodified and posterior flattening groups.

$10.8 \%$, and maximum frontal breadth by $8.5 \%$ in her 'antero-posterior' (bilobed) group compared with unmodified crania, a slightly smaller difference in maximum cranial breadth, but a larger difference in maximum frontal breadth than found here. Cheverud et al. (1992) reported an approximately 5\% lower cranial length in their 'fronto-occipitally' modified Peruvian sample, similar to the posterior flattening but less than the bilobed group here. With circumferential modification, Antón (1989) demonstrated significantly higher maximum cranial breadth by $7.5 \%$ compared with unmodified samples, and significantly lower maximum frontal breadth (XFB) by $5.7 \%$. In the present study, no significant differences in XFB were observed, and a similar difference in parietal breadth (XPB). Others have found a significantly higher cranial height $(\mathrm{BBH})$ among circumferentially modified Melanesian crania than unmodified crania (Blackwood \& Danby, 1955; Brown, 1981), while no difference was observed here. Differences in the patterning and extent of the effects of ACM on cranial angles between this and other studies were also observed (e.g. McNeill \& Newton, 1965; Antón, 1989). It is notable that our circumferential sample demon- strated a relatively mild modification compared with other samples (see Weiss, 1961, for examples of severe circumferential modification in the Andes) which may be a contributory factor to differences in results between studies, although differences in methods and small sample size in the current study may also be contributory factors.

Significantly greater facial flatness of the orbital area was found in the posteriorly flattened group than either the bilobed or circumferentially modified groups. While the first is the opposite of what might be expected in the light of Cheverud et al.'s views (1992), the latter is expected under Kohn et al.'s (1993) model. However, no significant difference was found between the bilobed and circumferential groups in facial flatness, although these were the two groups predicted to differ most in this respect. Additionally, facial flatness was greater in the circumferential group than the bilobed group, contra expectations from Kohn et al.'s (1993) model. It may be that Cheverud et al.'s (1992) 'fronto-occipital' modification and the bilobed modification studied here affect the cranium differently due to differences between groups in the precise detail of the way the modification was performed. This 
perhaps highlights the amount of variability subsumed within the major modification types commonly used, although again methodological differences and small sample size should be considered.

No significant effects of posterior flattening on facial morphology were found when compared with unmodified crania, consistent with Ewing's (1950) finding in Lebanese crania subjected to cradle-boarding and the low level of severity in this type of modification. The lack of effects of circumferential modification on facial morphology is contrary to the results from other studies, and may reflect a true difference between the circumferential group studied here and those of other studies, or differences in methods or sample sizes. The extent of gross visual circumferential modification varies substantially between populations, and its effects on facial morphology may vary accordingly.

Other studies have generally shown more marked effects of ACM on facial morphology. Methodological differences and small sample sizes, especially for facial measurements, may partly explain the general lack of significant differences. Also, since the cranial vault represents a much larger proportion of cranial volume than the face (Cheverud et al., 1992), even if affected to a similar extent as vault measurements, as Cheverud et al. (1992) suggest, they may be subject to greater relative measurement error. Particularly with small sample size this may cause difficulty in achieving statistical significance. Alternatively, the differences may be real and relate to interpopulation differences in the modification process.

Although other studies have found significant effects of ACM on the cranial base (e.g. Moss, 1958; McNeill \& Newton, 1965; Antón, 1989; Cheverud et al., 1992, Kohn et al., 1993), the measurements taken here did not permit a detailed study.

As noted above, posterior flattening was observed to be a generally mild form of ACM, and the relatively poor separation from the unmodified crania achieved in the canonical variates analysis reflected this. In some cases it was difficult to determine whether or not a cranium was unmodified or demonstrated mild posterior flattening, as an effectively continuous spectrum of cranial shape variation was observed. Indeed, the lack of clear distinction between unmodified and artificially modified crania can be problematic for a variety of modification types (e.g. Clark et al., 2007), but is a particular problem with such a mild form of ACM as posterior flattening. This may also have implications for the methodological approach taken here where crania were categorised as modified or unmodified from the outset as there may have been some degree of misclassification. Another approach which may provide an alternative means of assessing variability in cranial shape would be to pool data from all crania without prior assignment to one modification type or another, and to use this as a starting point to investigating cranial shape variability and clustering of cranial shapes within and between populations.

The results obtained here further highlight and add to the variability in results from previous studies. Although some authors (e.g. Antón, 1989; Cheverud et al., 1992) lament about the lack of consistency in results, we suggest that interpopulation variability in the modification process receives insufficient recognition as a potential cause of these discrepancies. This is reflected in the use of very broad categories of modification in some studies which subsume considerable variability in cranial shape. Cheverud et al. (1992) recognise that differences between their two populations showing 'fronto-occipital' modification may arise from interpopulation differences in details of the modification process, and state that 'generalizations should be restricted to similar extents and types of modification within local cultural traditions' (p. 343). However, they continue to compare broad categories in their subsequent study (e.g. Kohn et al., 1993). This suggestion could not be explored in the present study, and methodological differences between studies must also be considered as a factor contributing to this variability in results. The metric comparison of different populations showing superficially similar types of ACM will be an interesting area for future research to confirm whether such variation in results between studies does reflect, at least in part, population differences in ACM.

These results also support the conclusions of Rhode \& Arriaza (2006). They demonstrated that measurements thought to be unaffected by ACM, and therefore suitable for craniometric studies of population relatedness, are actually influenced by

Int. J. Osteoarchaeol. 20: 317-334 (2010) 
some types of ACM. Ten measurements (BPL, $\mathrm{NPH}, \mathrm{OBH}, \mathrm{OBB}, \mathrm{WCB}, \mathrm{NLH}, \mathrm{NLB}, \mathrm{ZYB}, \mathrm{MAB}$ and maxillo-alveolar length, not measured here) had been suggested to be suitable for this purpose as they were unaffected by ACM in some Argentinean groups (see Rhode \& Arriaza, 2006). Of these measurements, they found that only facial depth (BPL) and nasal breadth (NLB) were unaffected in both sexes observed in a sample of Chilean crania. A different pattern of results was obtained here (only orbital height, $\mathrm{OBH}$, showed significant differences), supporting their assertion that these measurements are differentially affected by ACM according to the population studied.

It should be remembered that any significant differences in cranial dimensions between the different types of modification could also relate in part to body size differences between the populations. However, it was not possible to test for such differences due to the relatively small numbers of unmodified crania from the individual sites and a lack of associated postcrania in which to examine potential body size differences. This is an area for further investigation which this and previous comparative studies involving different modification types and populations have not yet fully addressed.

This and previous studies have shown that ACM can have significant effects on the cranial vault, base and face. Future investigations should focus on variability resulting from apparently similar modification types. This will potentially refine our knowledge of the interactions between various elements of the cranium during growth beyond the information already gleaned from previous studies. The differences might result from small differences in the modification process itself, such as the position, intensity and duration of the application of the apparatus, or from other environmental or cultural factors which remain after the process of modification or which alter its effects. These factors are a component of the variation seen within populations showing a given modification type (Blackwood \& Danby, 1955). Variation within broad modification types (e.g. Weiss, 1961) and even within populations can be considerable, as observed in this study and highlighted by Blackwood \& Danby (1955). Variation between geographically close popu- lations practising apparently the same type of modification may itself be of interest in terms of the degree to which practices varied on a local basis, and the implications this might have for interaction between such groups (Hoshower et al., 1995).

\section{Conclusion}

Metric analysis was successfully used to characterise the effects of ACM on cranial vault and facial shape compared with unmodified crania. Measurements may be used to distinguish between different types of ACM. Although the patterns recorded broadly agreed with those of other studies, they differed in detail. This suggests that there may be considerable interpopulation differences in the precise effects of visually similar types of modification, a factor which warrants further investigation and greater recognition as a potentially contributory factor to differences in results between craniometric studies of ACM.

\section{Acknowledgements}

The research was made possible by the grants from the Hanley Fund and the Johnian Society Travel Exhibition (St. Johns College, Cambridge); the Cambridge University Worts' Travelling Scholars Fund and the H. E. Durham Fund (King's College, Cambridge).

The authors thank Alex Herrera, Kevin Lane, Camilo Dolorier Torres, Timoteo, Don Pancho and family, Felipe Livora, Pedro and Fraser Sturt for access to samples, help and assistance at the sites, and preparation of the figures. The authors also thank the editor and two anonymous reviewers for helpful feedback which substantially improved the manuscript.

\section{References}

Allison MJ, Gerszten E, Munizaga J, Santoro C, Focacci G. 1981. La práctica de la deformación craneana entre los pueblos Andinos Precolombinos. Chungará, (Arica, Cbile) 7: 238-260.

Int. J. Osteoarchaeol. 20: 317-334 (2010) 
Antón SC. 1989. Intentional cranial vault deformation and induced changes of the cranial base and face. American Journal of Physical Antbropology 79: 253267.

Antón SC, Weinstein KJ. 1999. Artificial cranial deformation and fossil Australians revisited. Journal of Human Evolution 36: 195-209.

Aufderheide AC, Rodríguez-Martín C. 1998. The Cambridge Encyclopedia of Human Paleopathology. Cambridge University Press: Cambridge.

Bass WM. 1995. Human Osteology: A Laboratory and Field Manual, (4th edn). Missouri Archaeological Society Inc: Special Publication 2.

Bjork A, Bjork L. 1964. Artificial deformation and craniofacial asymmetry in ancient Peruvians. Journal of Dental Research 43: 353-362.

Blackwood B, Danby PM. 1955. A study of artificial cranial deformation in New Britain. Journal of the Royal Antbropological Institute 85: 173-192.

Brothwell D. 1975. Possible evidence of a cultural practice affecting head growth in some Late Pleistocene East Asian and Australasian populations. Journal of Archaeological Science 2: 75-77.

Brown P. 1981. Artificial cranial deformation: a component in the variation in Pleistocene Australian Aboriginal crania. Archaeology in Oceania 16: 156167.

Cheverud JM, Kohn LAP, Konigsberg LW, Leigh SR. 1992. Effects of fronto-occipital artificial cranial vault modification on the cranial base and face. American Journal of Physical Antbropology 88: 323345.

Clark JL, Dobson SD, Antón SA, Hawks J, Hunley KL, Wolpoff MH. 2007. Identifying artificially deformed crania. International Journal of Osteoarchaeology 17: 596-607.

Cocilovo JA, Costa-Junqueira MA. 2001. La deformación artificial en el Período Arcaíco de Arica. Latin American Antiquity 12: 203-214.

Dingwall EJ. 1931. Artificial Cranial Deformation: A Contribution to the Study of Ethnic Mutilations. John Bale, Sons and Danielsson: London.

Ericksen MF. 1962. Undeformed pre-Columbian crania from the north sierra of Peru. American Journal of Pbysical Antbropology 20: 209-222.

Ewing FJ. 1950. Hyperbrachycephaly as influenced by cultural conditioning. Peabody Museum Papers 23: $1-99$.

Field A. 2005. Discovering Statistics Using SPSS. (2nd edn). Sage Publications Ltd: London.

Gerszten PC. 1993. An investigation into the practice of cranial deformation among pre-Columbian peoples of northern Chile. International Journal of Osteoarchaeology 3: 87-98.
Hatt G. 1915. Artificial moulding of the infant's head among the Scandinavian Lapps. American Antbropologist 17: 245-256.

Herrera A. 2005. Territory and Identity in the Pre-Columbian Andes of North-central Peru. PhD Thesis, University of Cambridge.

Hrdlička A. 1922. Aymara deformation in America. American Journal of Pbysical Antbropology 5: 400.

Hoshower LM, Buikstra JE, Goldstein PS, Webster AD. 1995. Artificial cranial deformation at the Omo M10 site: a Tiwanaku complex from the Moquegua Valley, Peru. Latin American Antiquity 6: 145-164.

Howells WW. 1973. Cranial variation in man. Peabody Museum Papers 67: 1-529.

Klecka WR. 1980. Discriminant Analysis. Sage University Papers Series: Quantitative Applications in the Social Sciences, No. 07-019. Sage: London.

Kohn LAP, Leigh SR, Jacobs SC, Cheverud JM. 1993. Effects of annular cranial vault modification on the cranial base and face. American Journal of Physical Antbropology 90: 147-168.

Lane K. 2007. The state they were in: community, continuity and change in the north-central Andes, 1000AD-1608AD. In Socialising Complexity: Structure, Integration and Power, Kohring S, and Wynne-Jones S (eds.) Oxbow Books: Oxford, 76-98.

Mason OT. 1887. Indian cradles and head flattening. Science 9: 617-620.

McNeill RW, Newton GN. 1965. Cranial base morphology in association with intentional cranial vault deformation. American Journal of Physical Antbropology 23: 241-254.

Moss ML. 1958. The pathogenesis of artificial cranial deformation. American Journal of Physical Antbropology 16: 269-286.

Neumann GK. 1942. Types of artificial cranial deformation in the eastern United States. American Antiquity 7: 306-310.

Newman MT. 1943. A metric study of undeformed Indian crania from Peru. American Journal of Pbysical Antbropology 1: 21-45.

Ozbek M. 2001. Cranial deformation in a subadult sample from Degirmentepe (Chalcolithic, Turkey). American Journal of Physical Antbropology 115: 238244.

Puciarelli HM. 1978. The influence of experimental deformation on craniofacial development in rats. American Journal of Physical Anthropology 48: 455-461.

Reichlen P. 1982. Contribución al estudios de las antiguas tecnicas de deformación cefálica en la costa del Perú. Revisto del Museo Nacional (Lima) 46: 381403.

Rhode MP, Arriaza BT. 2006. Influence of cranial deformation on facial morphology among prehistoric 
south-central Andean populations. American Journal of Physical Antbropology 130: 462-470.

Ross AH, Ubelaker DH, Guillén S. 2008. Craniometric patterning within ancient Peru. Latin American Antiquity 19: 158-166.

Schendel SA, Walker G, Kamisugi A. 1980. Hawaiian craniofacial morphometrics: average Mokapuan skull, artificial cranial deformation and the 'rocker' mandible. American Journal of Physical Antbropology 52: 491-500.

Snorrason E. 1946. Cranial deformation in the reign of Akhenaton. Bulletin of the History of Medicine 20: 601610.
Torres-Rouff C. 2002. Cranial vault modification and ethnicity in middle horizon San Pedro de Atacama, Chile. Current Antbropology 43: 163-171.

Weinstein KJ. 2005. Body proportions in ancient Andeans from high and low altitudes. American Journal of Pbysical Antbropology 128: 569-585.

Weiss P. 1961. Osteología Cultural: Practicas Cefálicas. 2da Parte: Tipología de las Deformaciones Cefálicas-Estudio Cultural de los Tipos Cetálicos y de Algunas Enfermedades Oseas. Universidad Nacional Mayor de San Marcos, Lima.

White TD, Folkens PA. 2000. Human Osteology, (2nd edn). Academic Press: London. 